$$
\text { كلية الإدارة والاقتصاد -جامعة الموصل }
$$

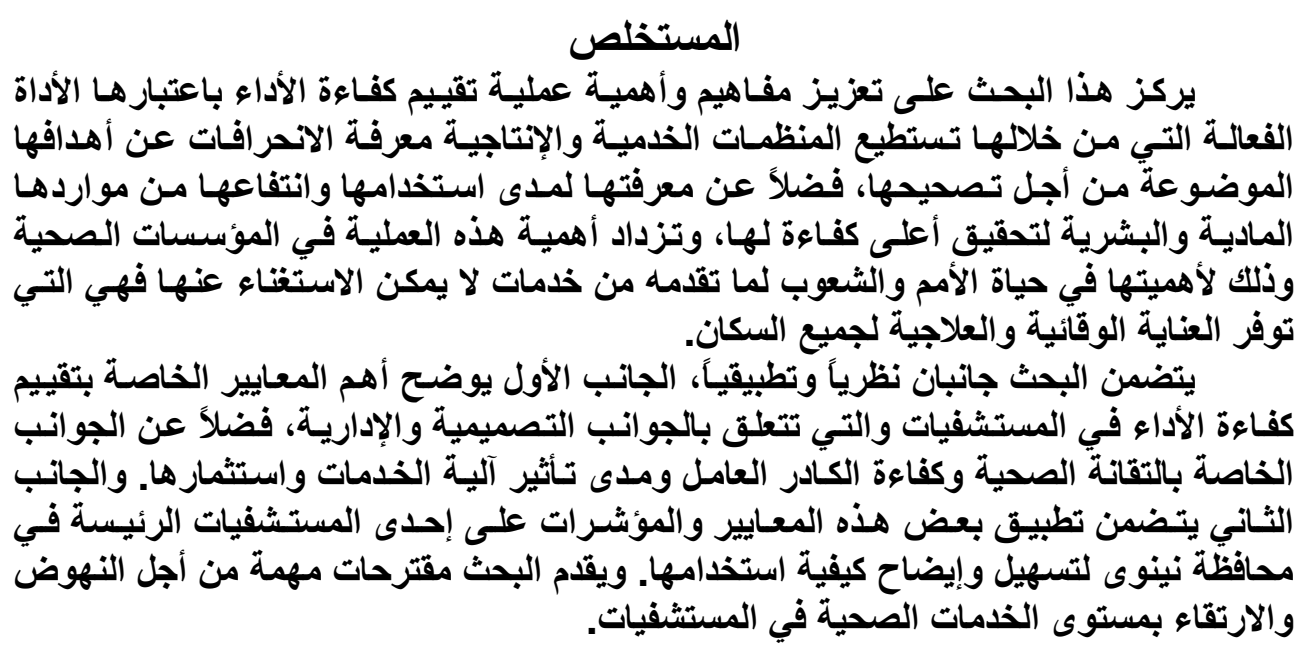

\title{
Apprisal of Efficiency Performance of the Health Institutions Applied Study
}

\section{Nizar Q. Al-Saffar}

Assistant Lecturer

Mosul Technical Institution

\begin{abstract}
The current study aims at promoting the major concepts and important elements of evaluating the performance efficiency as the effective tool by which the services and productive organizations can possibly monitor the goal deviations occurred. Additionally, the organization must know the benefits and usages of human and financial resources in order to gain the higher efficiency. This process can magnificently be increased among health institutions for potentially usages nationwide. This is because the services are indispensable for public care and health prevention.
\end{abstract}

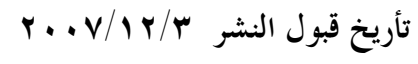

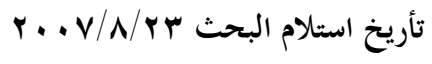




\section{الصفار [؛ ؛}

Theoretical and practical methods have been transcended; first clarify the special standards of evaluating performance in hospitals, they are structural, managerial, IT health care, personnel andd services dynamics. Second, the application of some standards and indicators on one of major hospitals at Ninavah governorate is posited, in order to show usages. Some recommendations have been proposed to promote the health services in hospitals.

لكي تحقق المنظمات الخدمية و الإنتاجية أهدافها بفاعلية وكفاءة عالية لابد لها الأها

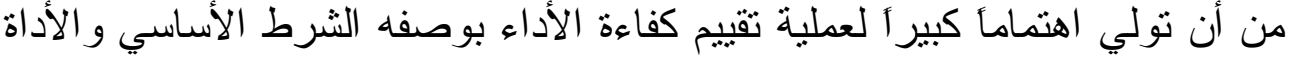

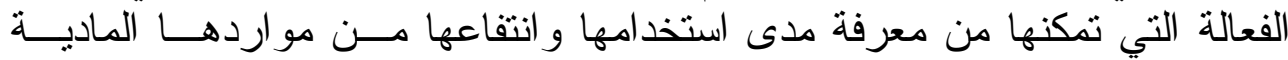

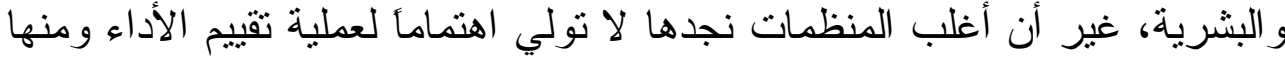

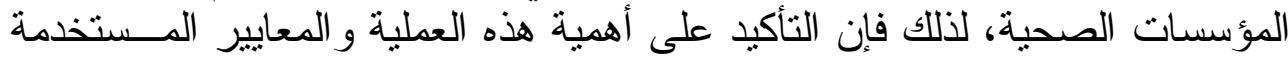

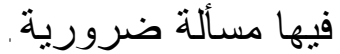

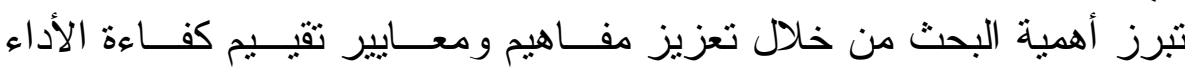
أهمية البحث

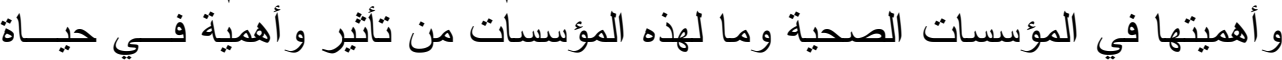

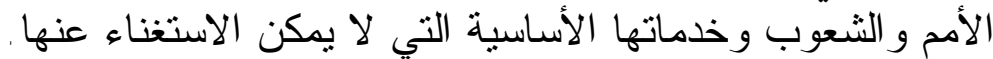
مشكلة البحث

تتحدد مشكلة البحث بعدم إعطاء المؤسسات الصحية في العــراق الاهتمـــام الكافي لمعظم المعايير و المؤشر ات المختلفة لعملية تقييم كفاءة الأداء.

يفتزض البحث أن هناك انحر افأ في قيم معايير ومؤشر ات تقييم كفــاءة أداء فرضية البحث

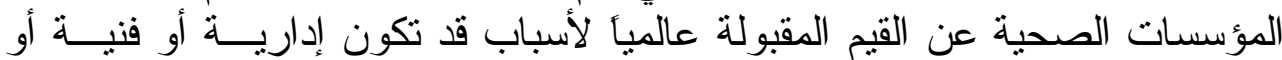

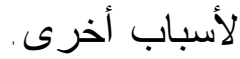

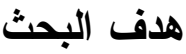

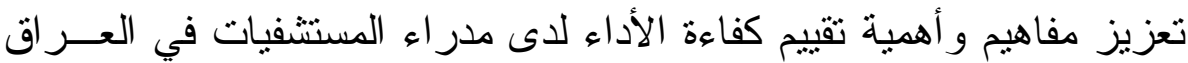

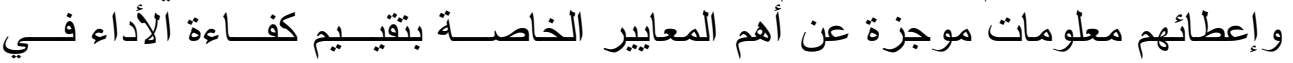

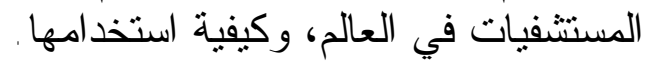


تم اعتماد المنهج التحليلي المقارن من خلال المقارنة مع قيم بعض المعــايير

\section{منهج البحث}

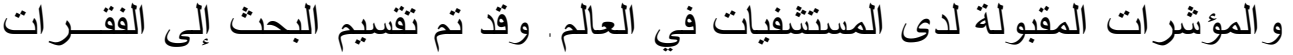

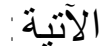

ويتضمن مفهوم و أهمية تقييم كفاءة الأداء و أهم المعايير المستخدمة في تقييم

$$
\text { أولاًا - الجانب النظري }
$$

كفاءة الأداء في المستشفيات في العالم .

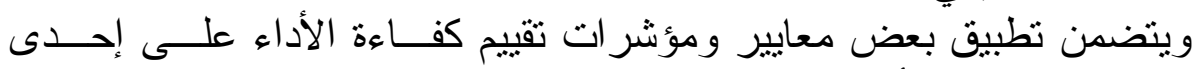

$$
\text { ثانياً - الجاتب التطبيقي }
$$

المستشفيات العر اقية من أجل تبسيط و إيضاح كيفية استخدامها.

\section{الجانب النظري مفهوم تقييم كفاءة الأداء}

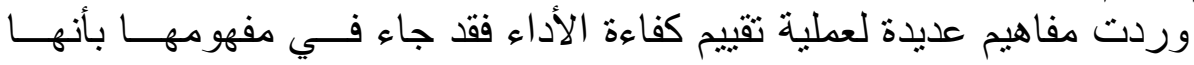

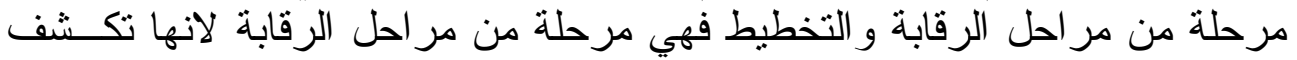

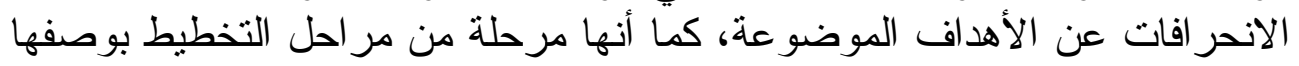

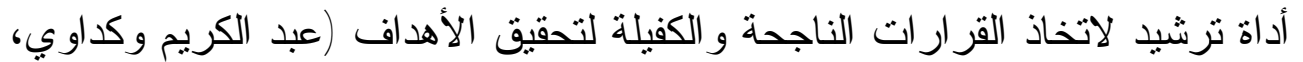

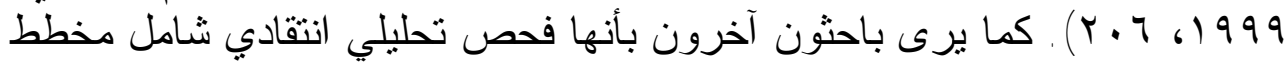

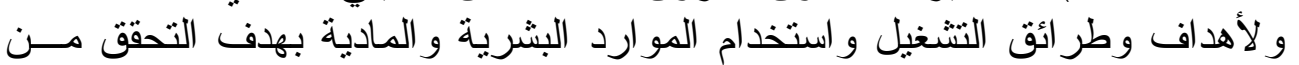

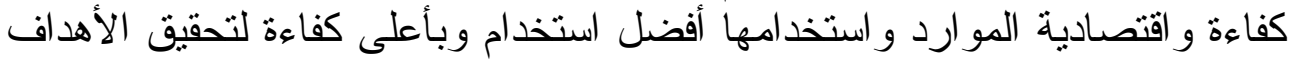

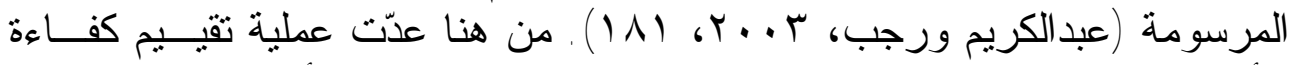

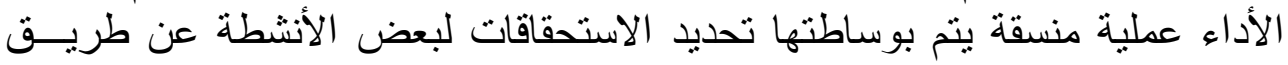

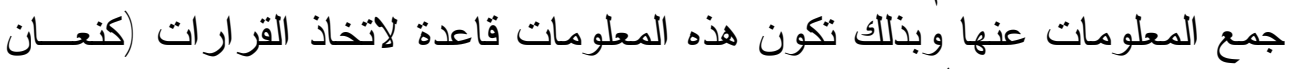

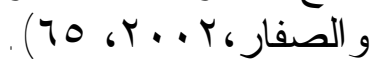

\section{أهمية تقييم كفاعة الأداء}

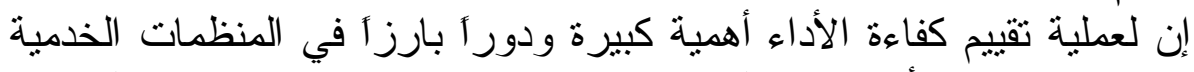

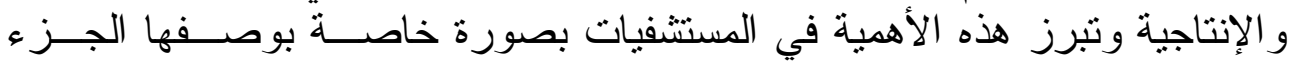

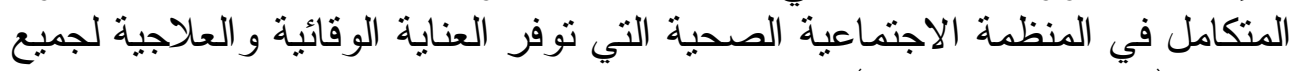

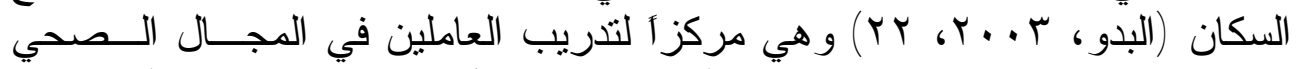

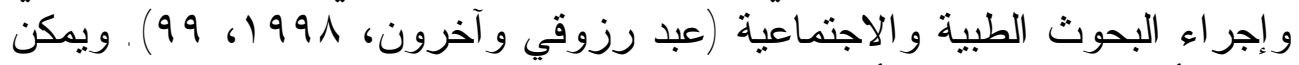

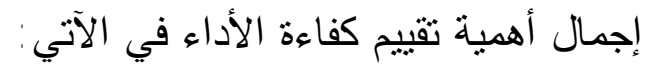

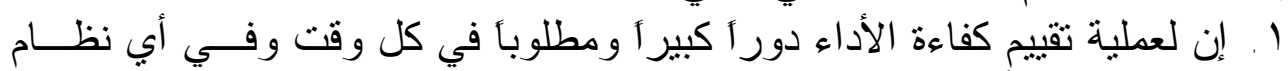

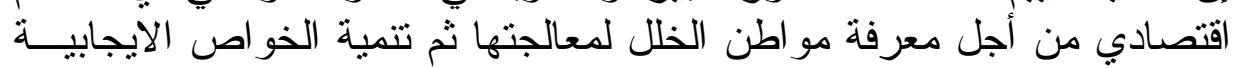

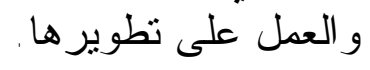




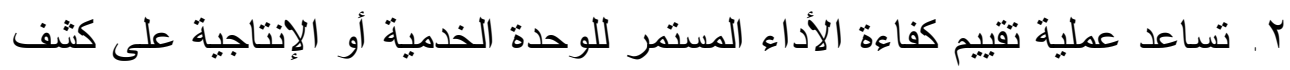

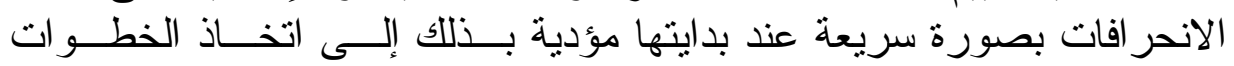

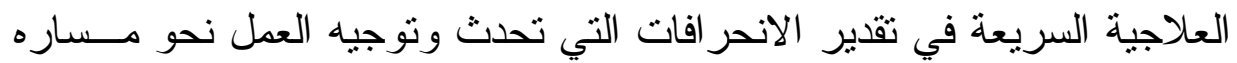

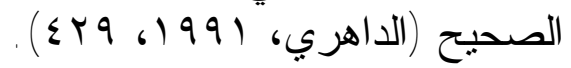

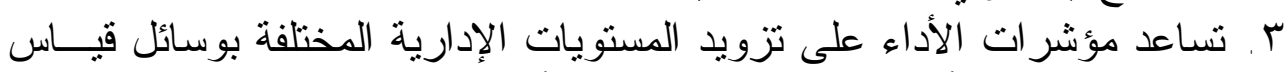

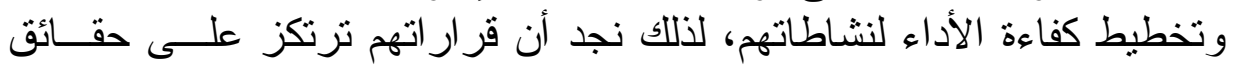

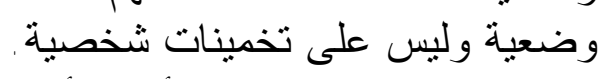

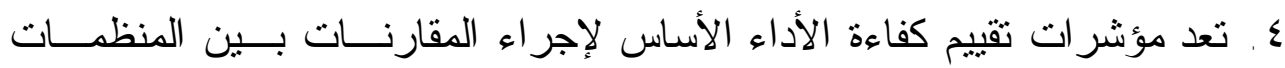

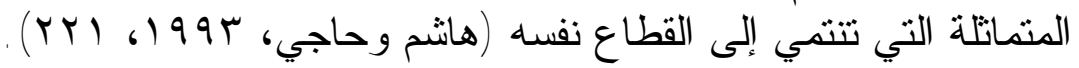

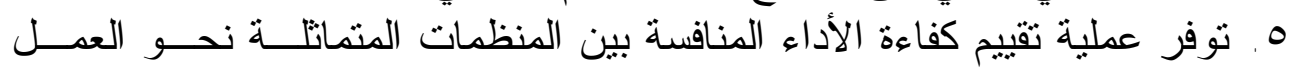

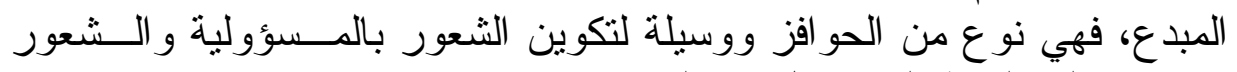
بالانتماء إلى الجهة التي يعمل بهاء الفر الفرد.

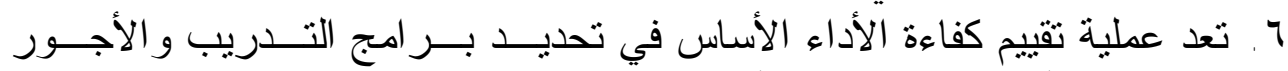

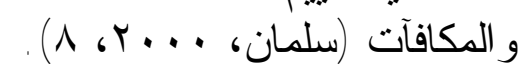

معايير تقييم كفاءة الأداء

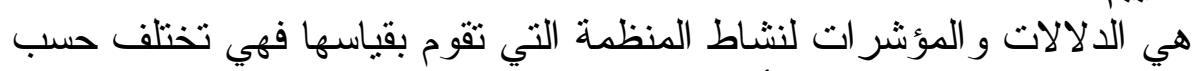

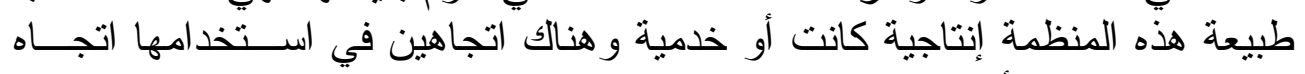

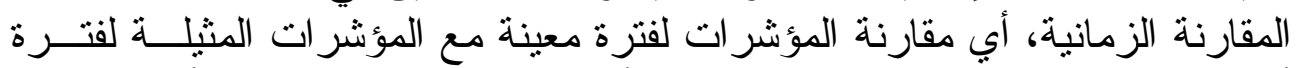

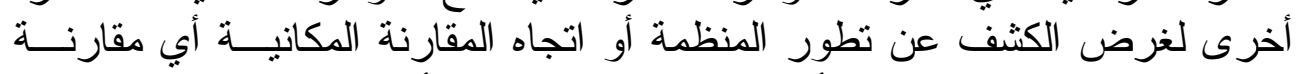

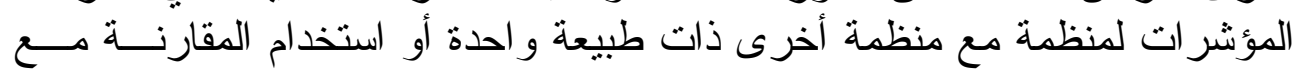
معايير ومؤشر ات قينياسية. وفيما يأتي أهم المعايير المستخدمة في تقييم كفاءة المستـشفيات: (البيــاتي، ( ) r r 4 ، r...)

\section{() (المعايير التصميمية}

و هي المعايير الخاصة بموقع المسنتفيات وحجمها وتصميمها التي لهــا دور كبير في أد"ائها. r المعايير الإدارية وهي المعايير الخاصة (بالتخطيط، التدريب، الجوانب المالية، الاستعلامات، الزيار ات، الجو انب الأمنية) . 


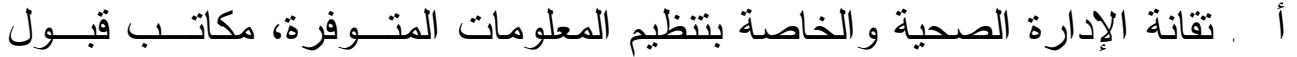

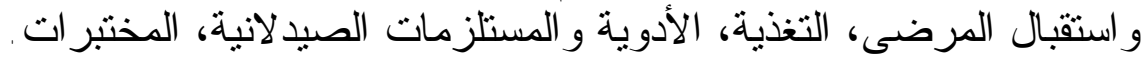

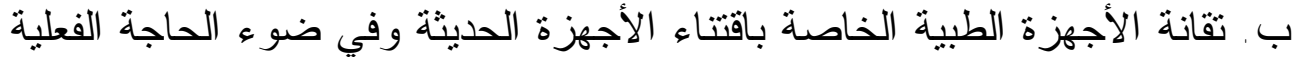

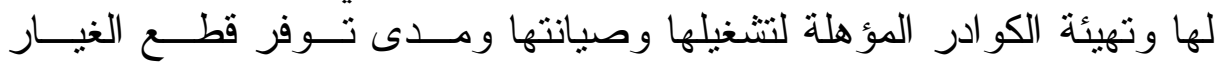
الضرورية لانجاز عملية الصيانة.

ت. تقانة الهندة الصحية الخاصة بالمستلزمات الصات الصحية و التتظيف و التعقيم وكل ما

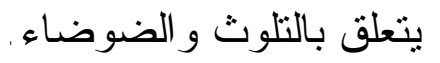

؛) معايير ومؤشرات إحصائية لتقييم أداء الكادر العامل في المستثفيات ومــدى

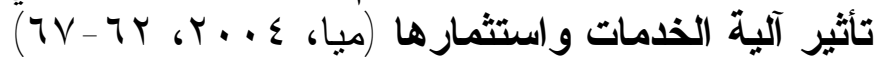

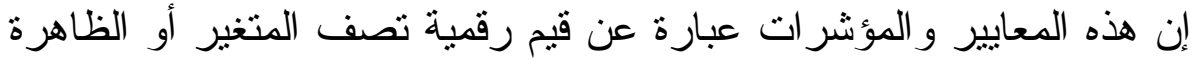

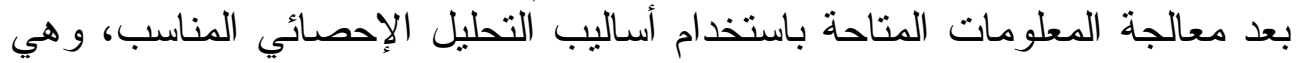

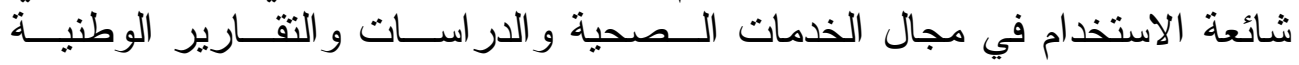

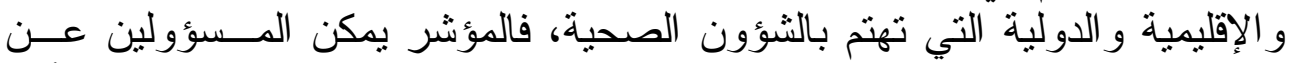

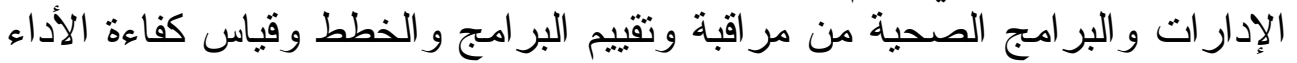

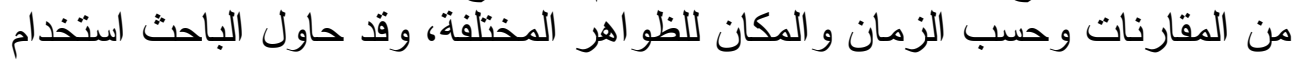

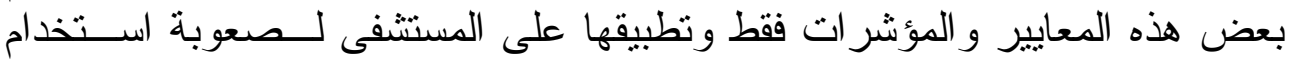

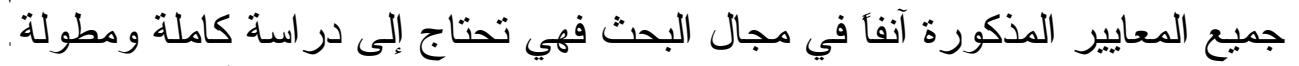

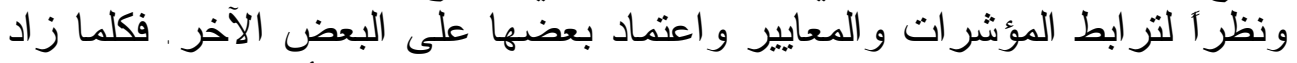

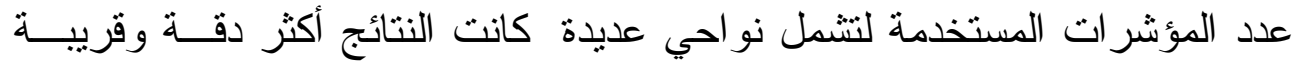

وفيماً بأتي أهم هذه المؤشر ات المستخدمة عالمياً:

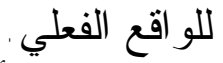

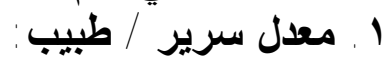

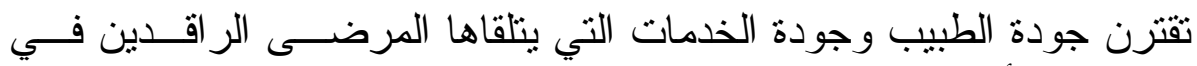

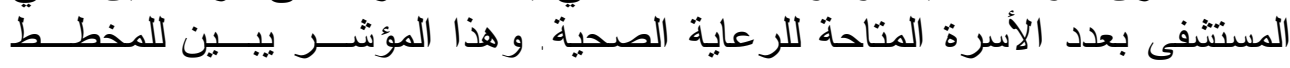

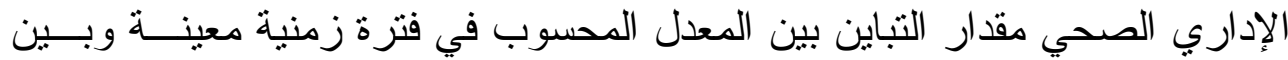

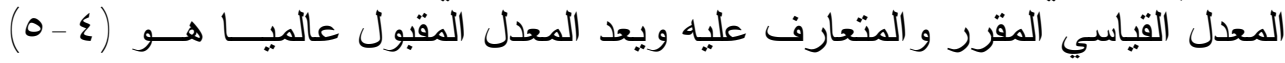

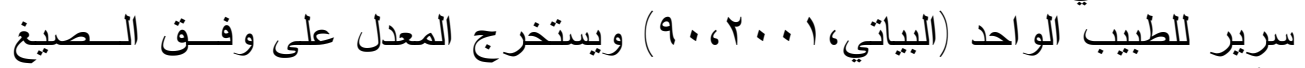

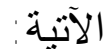

مجموع أسره المستثفى في فترة زمنية معينة

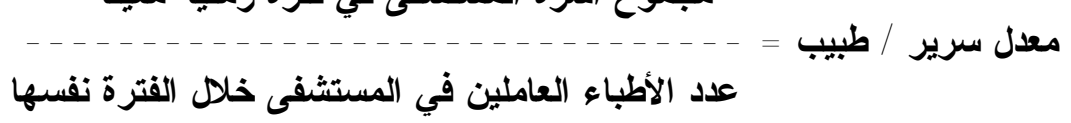




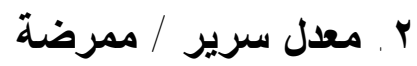

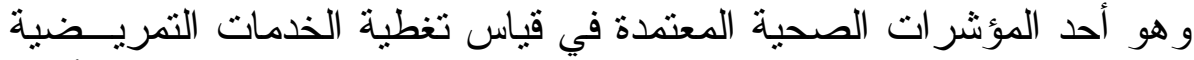

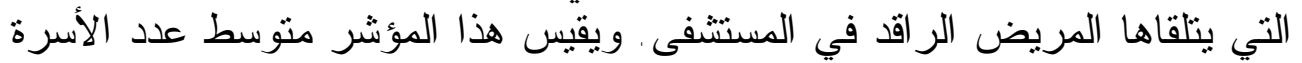

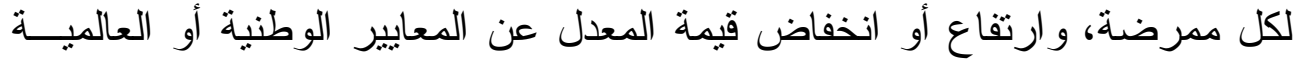

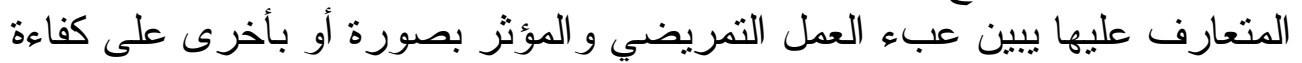

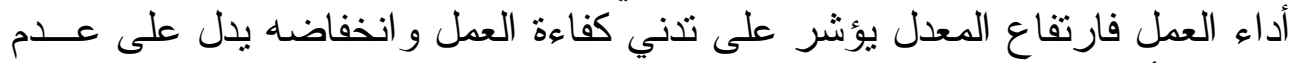

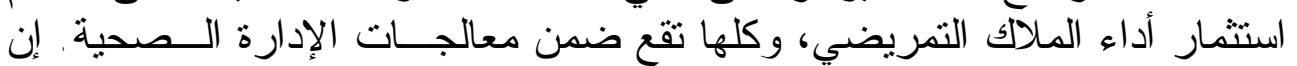

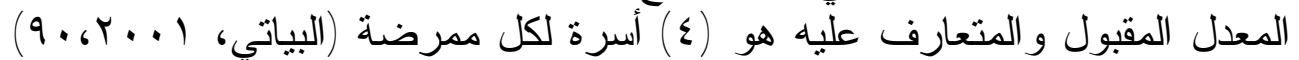
ويستخدم المعدل وفق الصيغ الآتية:

\section{العدد الكلي للأسرة في المستثفى في فترة زمنية معينة

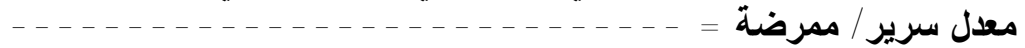 إجمالي عدد الممرضات خلا الفترة نفسها}

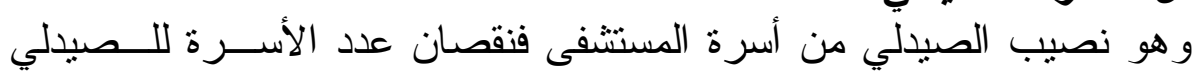

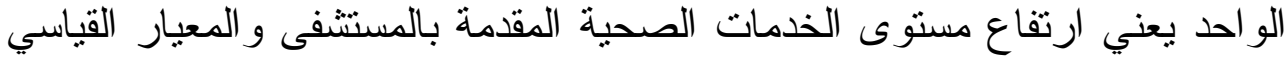

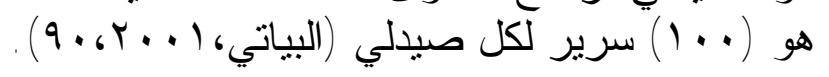

مجموع أسره المستثفى في فترة معينة

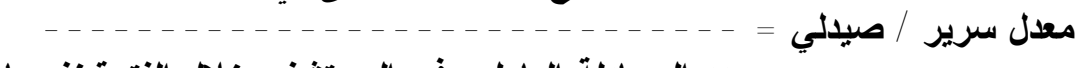
عدد الصيادلة العاملين في المستثفى خلا الفترة نفسها

؛ ـ معدل سرير / أخصائي التحليل المختبري

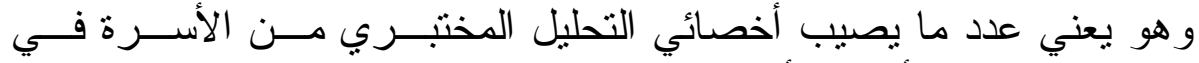

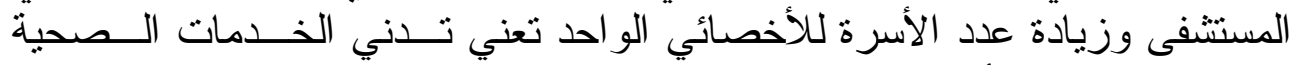

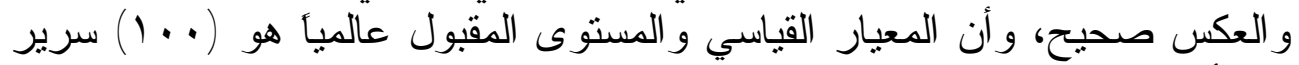

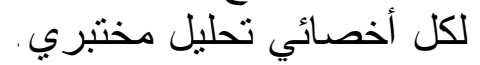

\section{ه. معدل سرير / أخصائي التغذية}

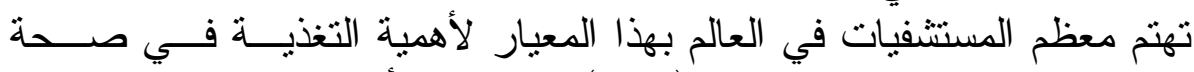
المريض و المستوى المقبول عالمياً هو ( . (1) سرير لكل أخصائي تغذية. 
7 ـ معدل سرير / أخصائي الخدمة الاجتماعي

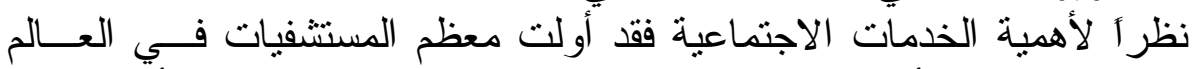

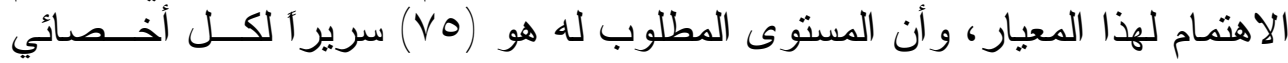
خدمات اجتماعية.

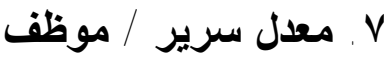

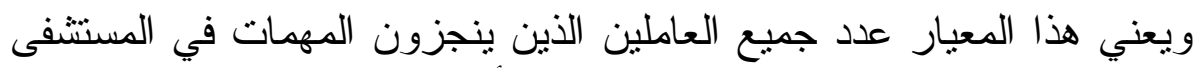

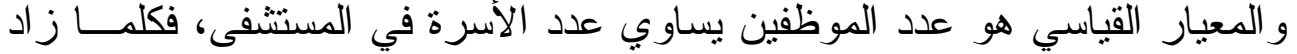

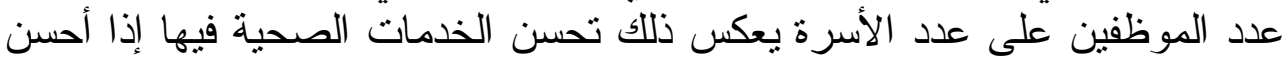

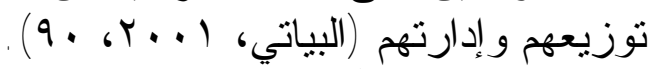

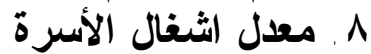
يعكس هذا المؤشر كثافة المكوث (مدة بقاء المريض في في المستـشفى) فكلمـــا

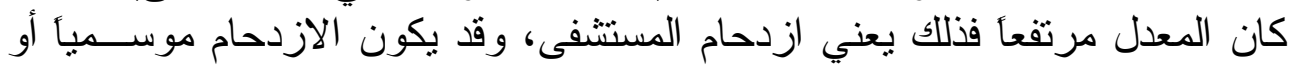

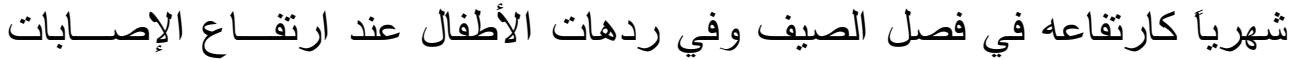

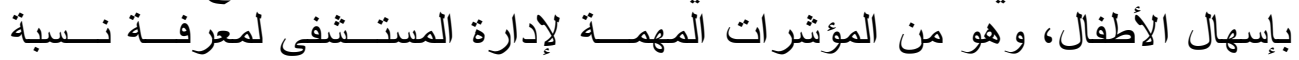

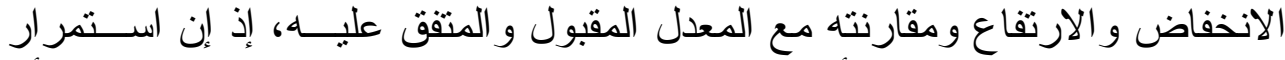

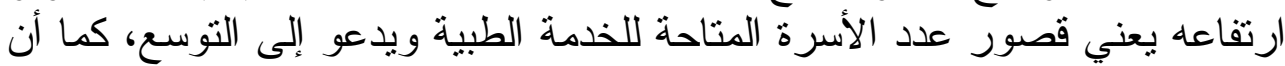

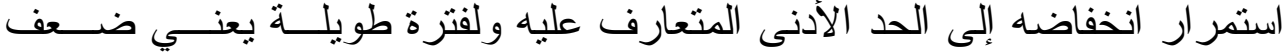

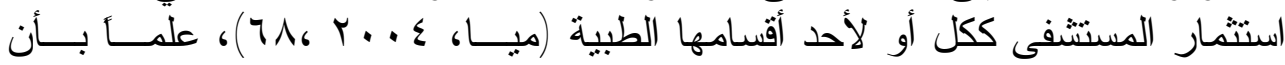

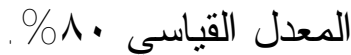

\section{مجموع أيام المكوث خلال سنة}

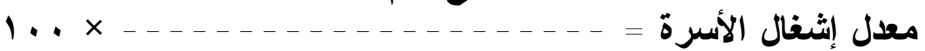

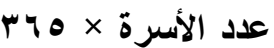

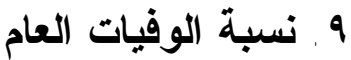

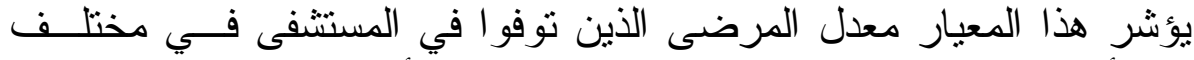

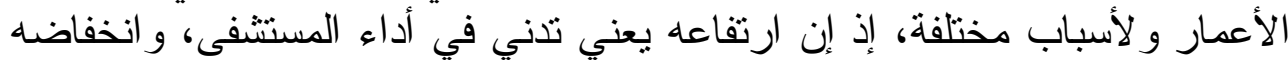

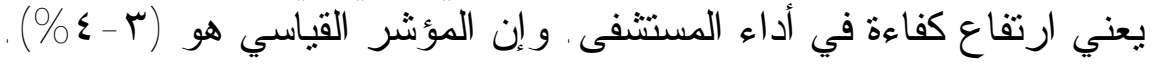

\section{مجموع الوفيات في المستثفى خلال فترة معينة

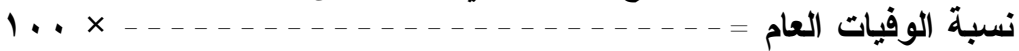 \\ مجموع المرضى الر اقدين خلا القترة نفسها}

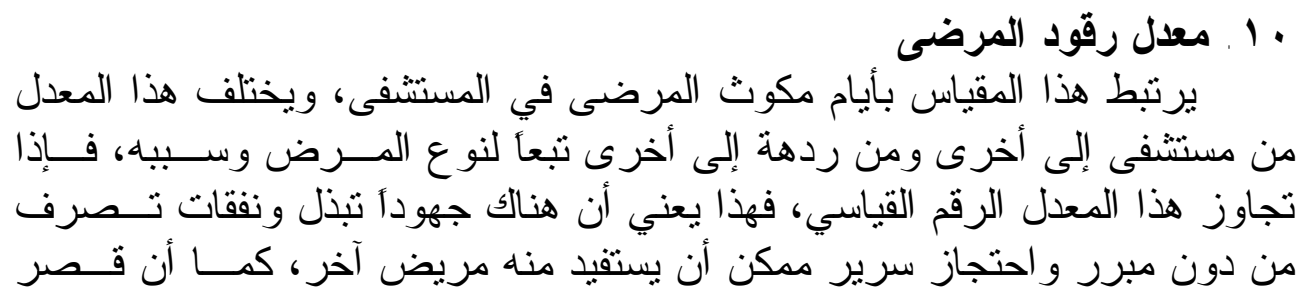




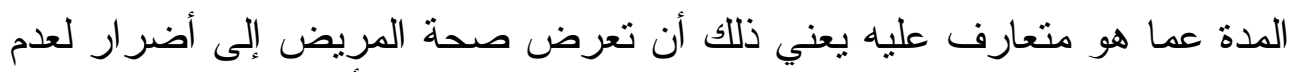
إكمال مدة العلاج المطلوب ـ و المعدل القياسي المقبول هو ل أيام.

مجموع عدد أيام مكوث المرضى خلا فترة معينة

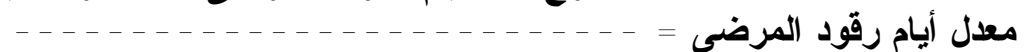
مجموع عدد المرضى الر اقدين خلا الفترة نفسها

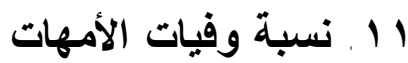

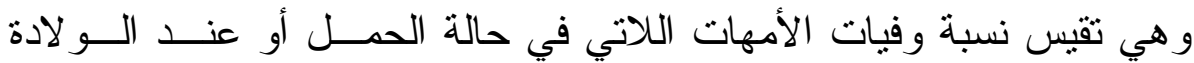

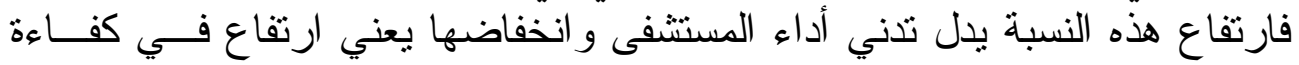
المستشفى، و النسبة القياسية هي بـ \% وتستخدم في مستشفيات الو لادة فقط.

مجموع وفيات الامهات نتيجة الحمل

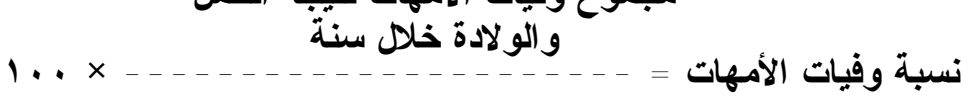

مجموع عدد حالات الولادات الحية

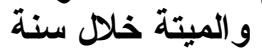

ب ا ب النسبة الوفيات في التلوث

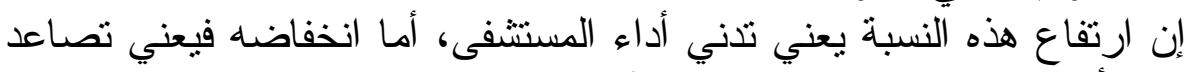

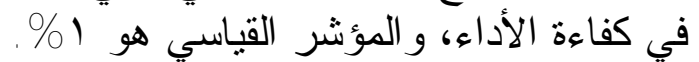

عداد حالات التلوث خلال سنة

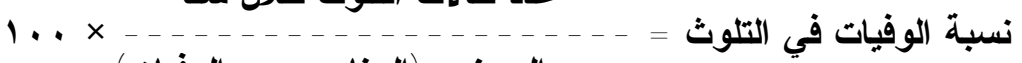

عدد المرضى (المغادرون + الوفيات)

خلا الفترة نفسها

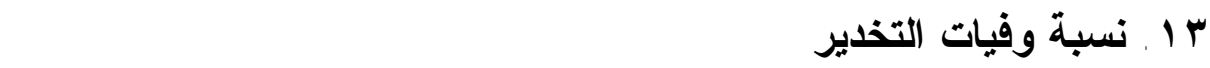

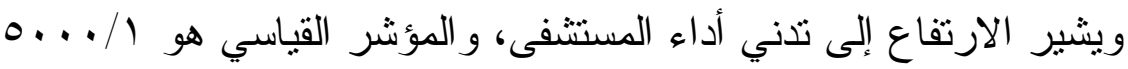

مجموع عدد الوفيات نتيجة التخدير خلاء سنة التهن

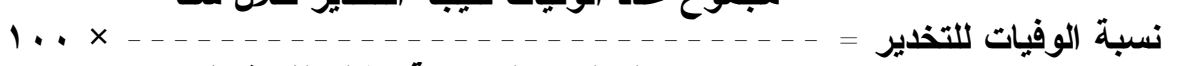

مجموع عدد العمليات الجراحية خلا الفترة نفسها

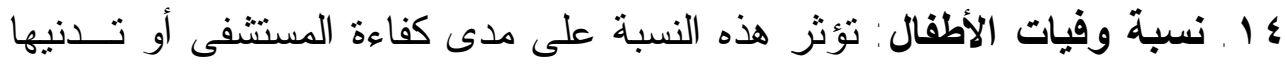

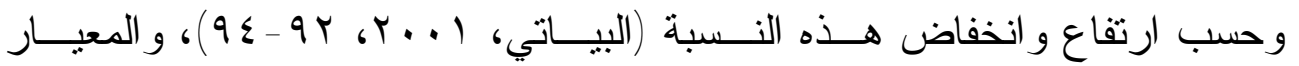
القياسي هو r\%

عدد وفيات الأطفال عمر (ه - r l) سنة خلا

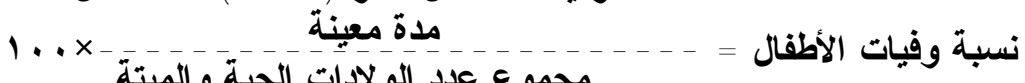

مجموع عدد التولادات الحيةّة والميتّة

خلال الفترة نفسها 


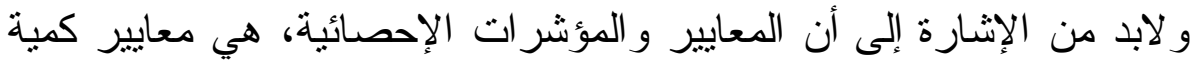

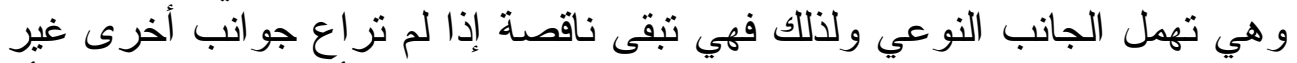

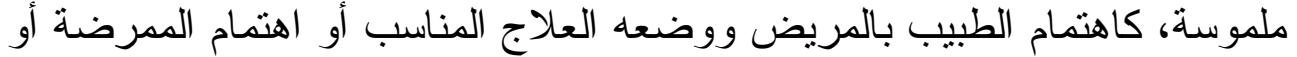

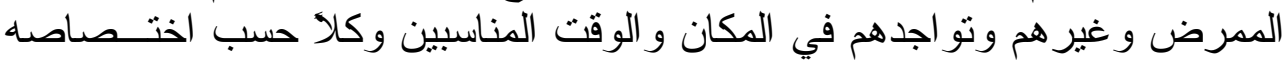

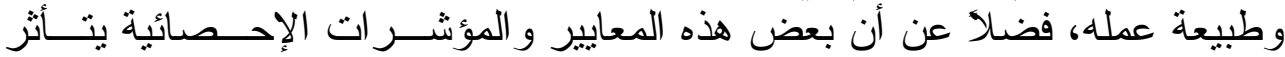

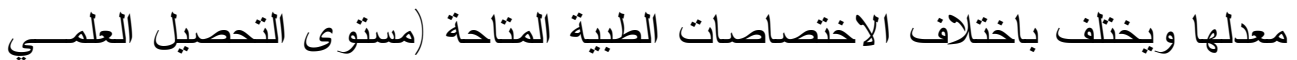

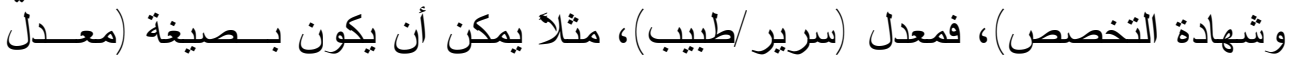

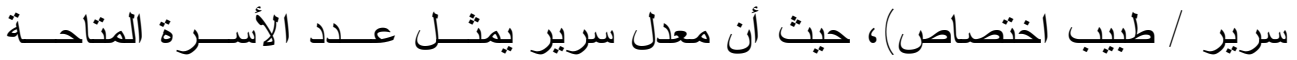

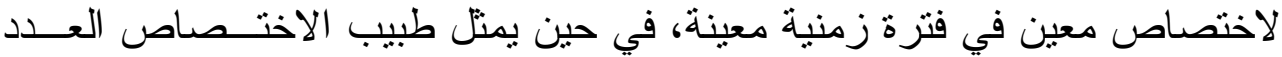

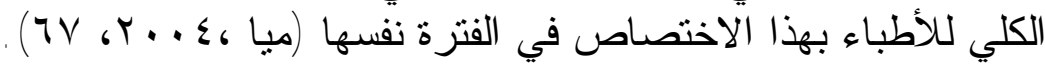

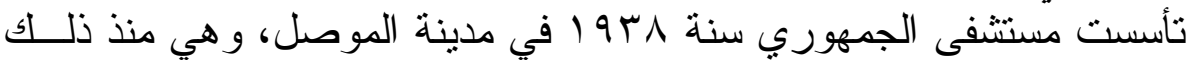

الجاتب التطبيقي

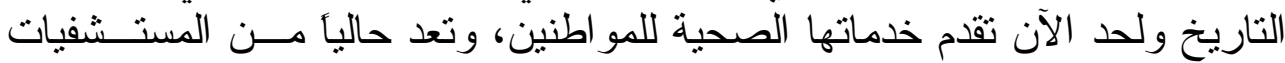

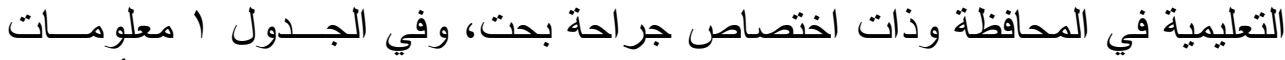

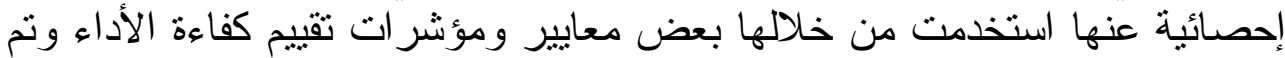
مقارنتها مع المعايير القياسية، وكما موضح بعض أدناه:

\begin{tabular}{|c|c|c|c|}
\hline \multicolumn{4}{|c|}{ ائية عن مستثة 1 الجدا } \\
\hline \multicolumn{3}{|c|}{ السنة } & \multirow[b]{2}{*}{ المعلومات } \\
\hline$r \ldots q$ & $r \ldots \theta$ & $Y \ldots \varepsilon$ & \\
\hline rT. & rT. & rT. & عدد الأسرة \\
\hline rq4 & $T \leqslant \varepsilon$ & TTV & عدد الأطباء \\
\hline$\sum Y r$ & $\varepsilon r \mu$ & $\sum 1 \wedge$ & عدد الممرضات و الممرضين" \\
\hline TO & ro & $r \xi$ & عدد الصيادلة \\
\hline- & - & - & عدد أخصائي التغذية \\
\hline 9 & $\Lambda$ & $\Lambda$ & عدد أخصائي التحليل المختبري \\
\hline- & - & - & عدد أخصائي العلاج الطبي \\
\hline- & - & - & عدد موظفي الخدمة \\
\hline 1.11 & $9 \pi 1$ & $9 \leqslant \wedge$ & عدد الموظقين \\
\hline IVVIT & 10707 & IVAVO & عدد الراقدين \\
\hline 104 & $11 \mathrm{~V}$ & $1 \leqslant \wedge$ & عدد وفيات الر اقدين \\
\hline $00 \pi r q$ & 01917 & 00910 & ايام المكوث \\
\hline & & 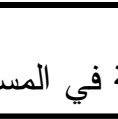 & (المصدر: العدد يمثل مجمو الإحصاء في المسنتً \\
\hline
\end{tabular}


ا ـ معدل الأسرة / طبيب

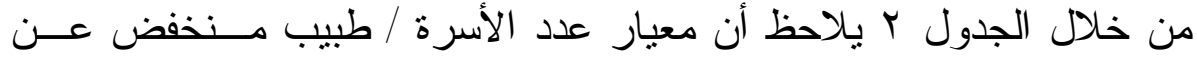

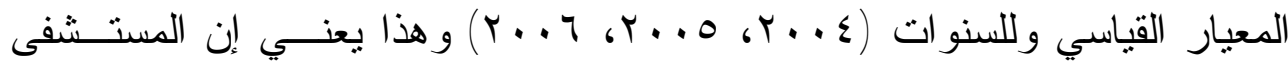

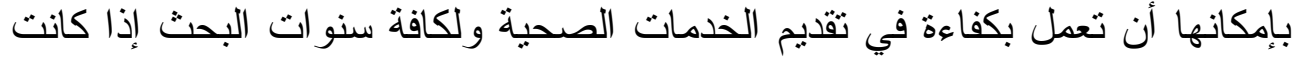

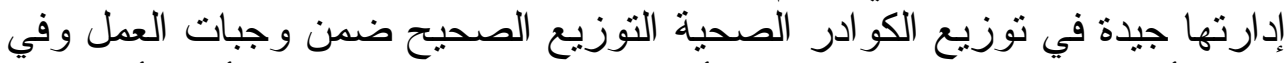

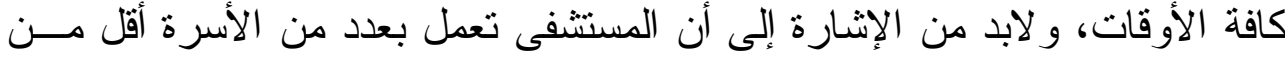

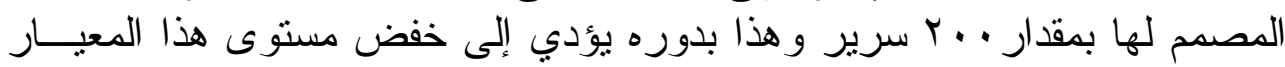

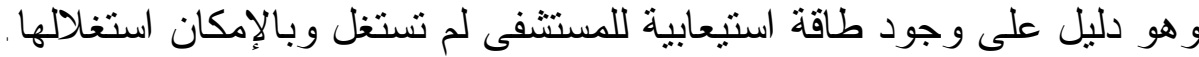

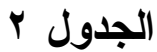

معدل عدد الأسرة لكل طبيب

\begin{tabular}{|c|c|c|}
\hline المعيار القياسي & معدل الأسرة / طبيب & 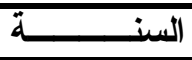 \\
\hline ه سرير لكل طبيب & $1, r$ & $\uparrow \ldots \varepsilon$ \\
\hline$=$ & $1, r$ & $r \ldots o$ \\
\hline$=$ & 1,1 & $r \ldots T$ \\
\hline
\end{tabular}

\section{r ا ب معدل الأسرة / ممرضة}

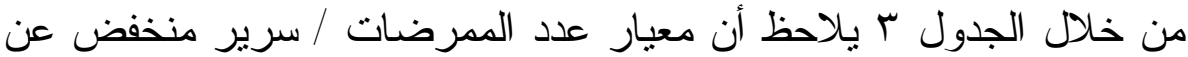

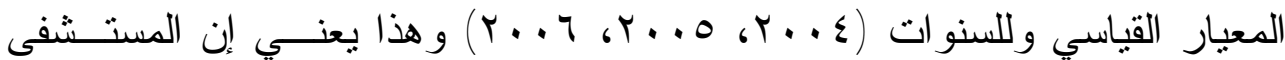

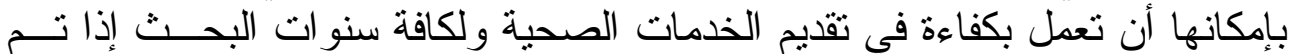

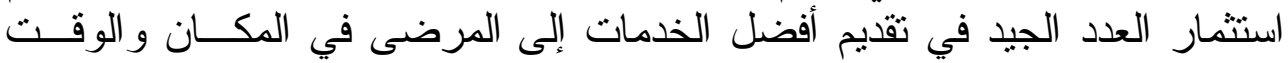
المناسب وتم توزيعهم بشكل جيد ضمن وجبات العمل .

\begin{tabular}{|c|c|c|}
\hline \multicolumn{3}{|c|}{ معدل عدد الأسدرة لكل ممرضة } \\
\hline المعيار القياسي & معدل الأسرة / ممرضة & 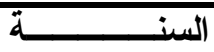 \\
\hline r سرير لكل ممرضة & $\cdot, 1 / 7$ & $r \ldots \varepsilon$ \\
\hline$=$ & $\therefore, 10$ & $r \ldots o$ \\
\hline$=$ & $\cdot, 1 \times 7$ & $r \ldots T$ \\
\hline
\end{tabular}

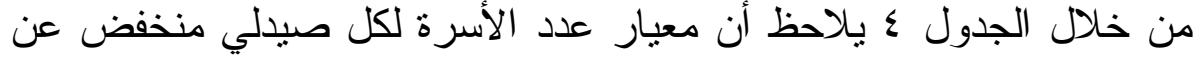

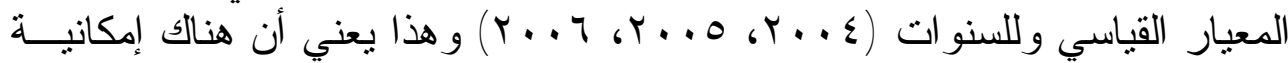




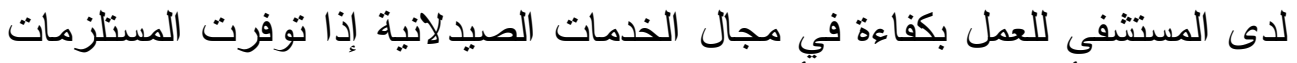

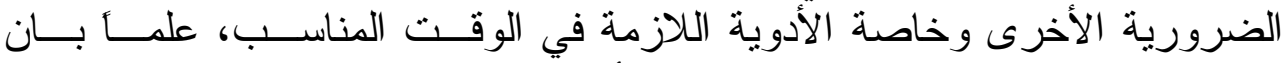

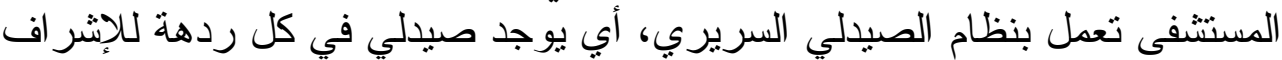

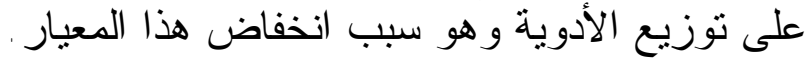

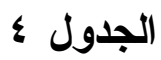

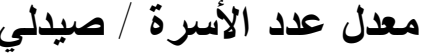

\begin{tabular}{|c|c|c|}
\hline المعيار القياسي & معدل الأسرة / صيدلي & السنـــــــــــة \\
\hline .. أسرير لكل صيدلي & $1 \Gamma, r$ & $r \ldots \varepsilon$ \\
\hline$=$ & $T, Y$ & $r \ldots 0$ \\
\hline$=$ & $T r, r$ & $r \ldots r$ \\
\hline
\end{tabular}

المصدر: قسم الإحصاء في المستشفى.

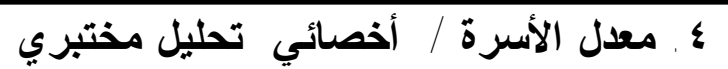

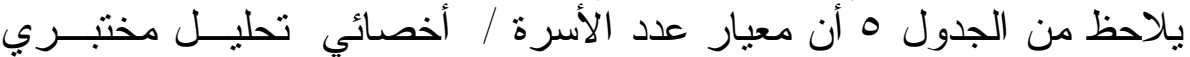

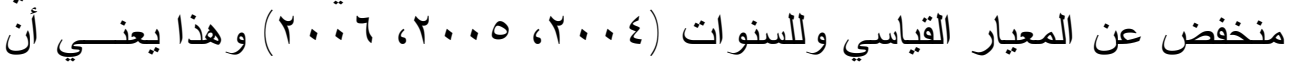

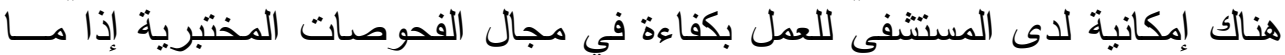
توفرت المستلزمات الضرورية الأخرى للعمل المختبري.

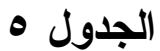

معدل عدد الأسرة / أخصائي تحليل مختبري

\begin{tabular}{|c|c|c|}
\hline المعيار القياسي & معدل الأسرة / أخصائي التحليل المختبري & السنـــــة \\
\hline ·. . سرير لكل أخصائي & $\varepsilon$ & $r \ldots \varepsilon$ \\
\hline$=$ & $\varepsilon$. & $r \ldots o$ \\
\hline$=$ & $r 0,0$ & $r \ldots T$ \\
\hline
\end{tabular}

المصدر : قسم الإحصاء في المستشفى.

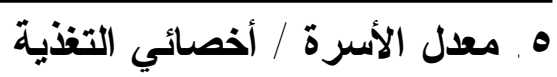

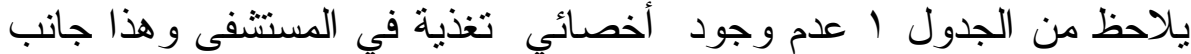

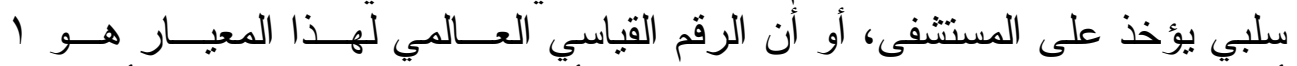

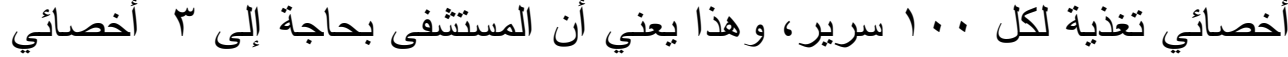

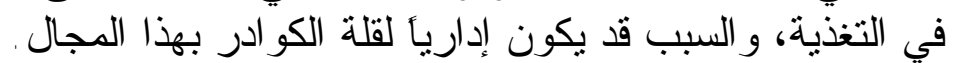

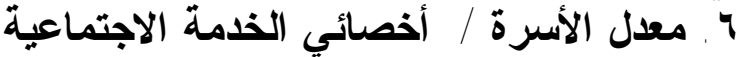

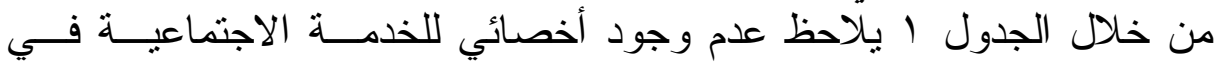

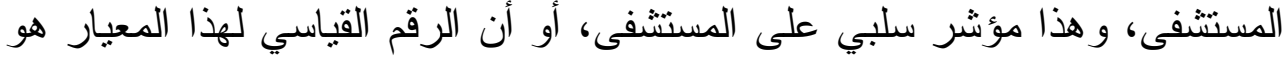

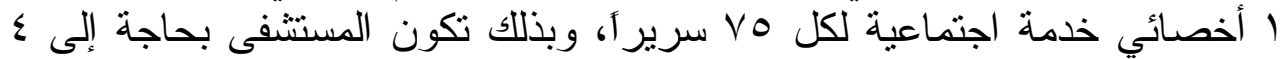

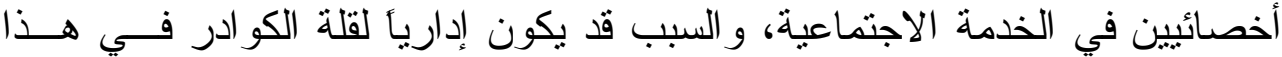

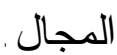




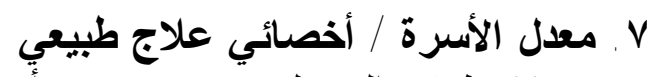

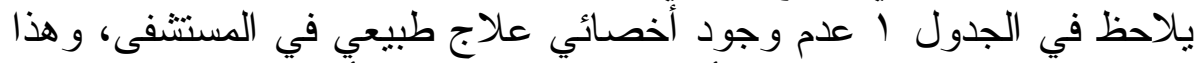

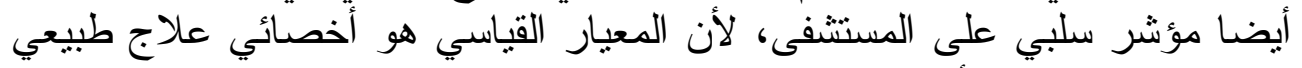

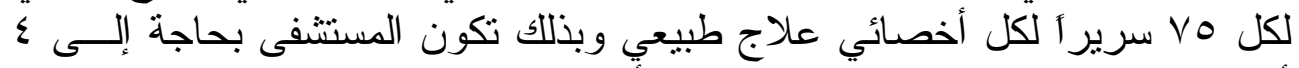

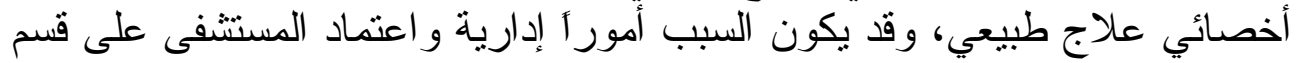

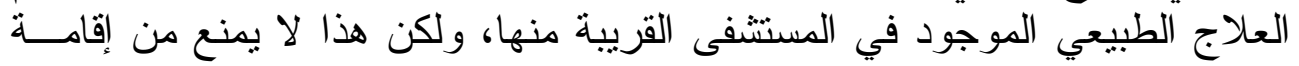

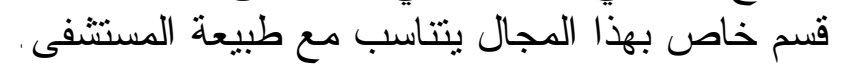

\section{1. معدل الأسرة / عدد الموظفين}

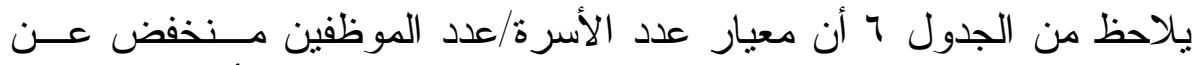

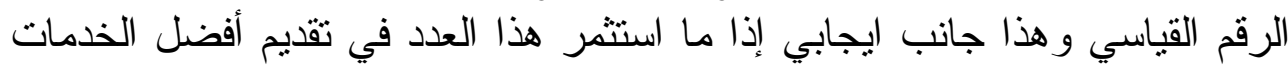

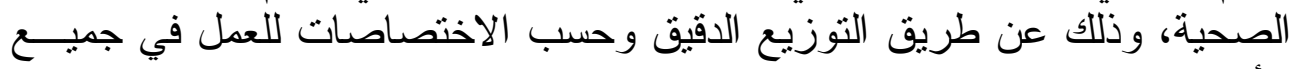

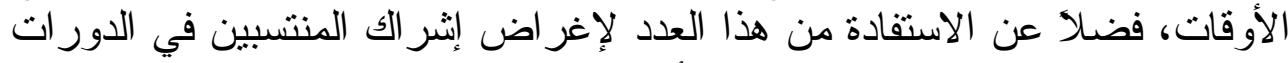

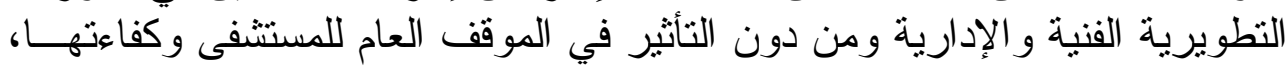

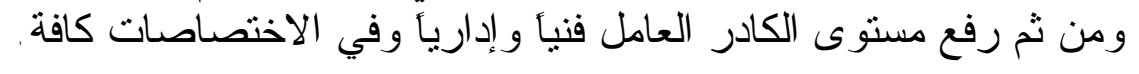

\begin{tabular}{|c|c|c|c|c|c|}
\hline \multicolumn{6}{|c|}{ 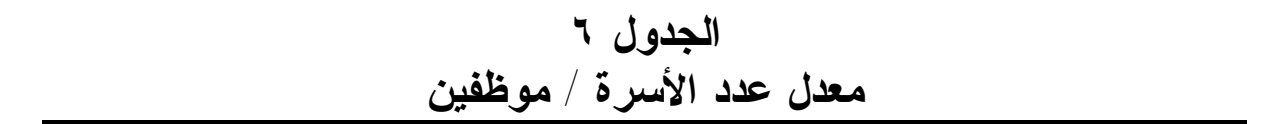 } \\
\hline \multicolumn{2}{|c|}{ المعيار القياسي } & \multicolumn{3}{|c|}{ عدد الأسرة / عدد الموظفين } & السنة \\
\hline \multicolumn{2}{|c|}{ | 1 موظف لكل سرير } & \multicolumn{3}{|c|}{,,$r r$} & $\overline{r \ldots \varepsilon}$ \\
\hline \multicolumn{2}{|c|}{$\begin{array}{l}= \\
= \\
=\end{array}$} & \multicolumn{3}{|c|}{$\cdot, r \varepsilon$} & $r \ldots o$ \\
\hline$\equiv$ & & & 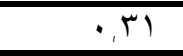 & & $r \ldots r$ \\
\hline & \multicolumn{3}{|c|}{ المصدر : قسم الإحصاء في المستتشىى } \\
\hline \multicolumn{6}{|c|}{ 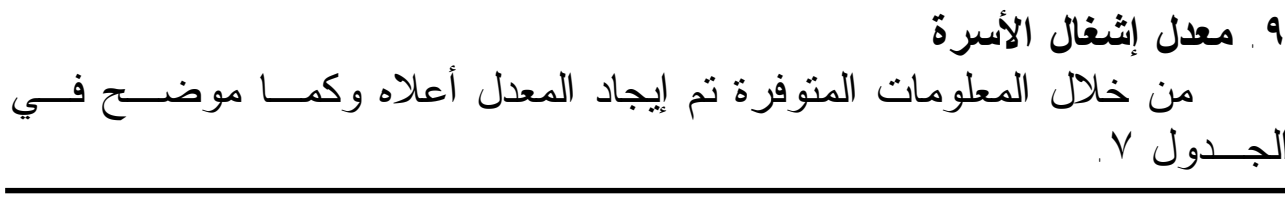 } \\
\hline \multicolumn{6}{|c|}{$\begin{array}{c}\text { معدل الثغال الأسرة } \\
\text { معرة }\end{array}$} \\
\hline $\begin{array}{c}\text { المعيار القياسي } \\
\text { (\%) }\end{array}$ & \multicolumn{2}{|c|}{ معدل انثشال الأسرة } & عدد الأسرة & 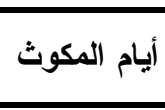 & السنة \\
\hline$\lambda \cdot$ & \multicolumn{2}{|c|}{$\varepsilon V, \Lambda$} & rr. & 00910 & $r \ldots \varepsilon$ \\
\hline$=$ & \multicolumn{2}{|c|}{$\xi \xi, 0$} & rr. & 01914 & $r \ldots o$ \\
\hline$=$ & \multicolumn{2}{|c|}{$\varepsilon v, r$} & rT. & $004 r 9$ & $r \ldots r$ \\
\hline
\end{tabular}




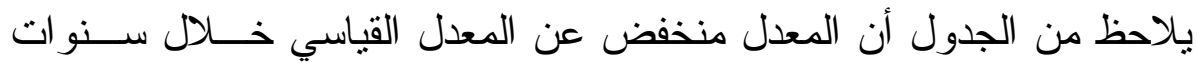

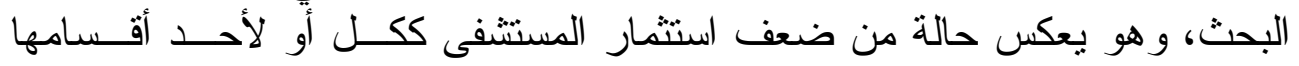
الطبية.

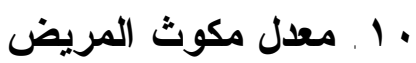
من خلال المعلومات المتوفرة يمكن إيجاد هذا المعدل. وكما موضــحـ فــي

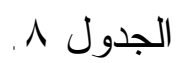

\begin{tabular}{|c|c|c|c|c|}
\hline \multicolumn{5}{|c|}{ معدل مكوث المريضول } \\
\hline القياسيار & معلد مكوث & عدد المرضى اقدين & ايام المكوث & السنة \\
\hline أيام V & $r, 1$ & TVAVO & 00910 & $r \ldots \varepsilon$ \\
\hline$=$ & $r, r$ & 10707 & 01917 & $r \ldots o$ \\
\hline$=$ & $\overline{r, 1}$ & IVVIT & $004 \pi q$ & $r \ldots r$ \\
\hline
\end{tabular}

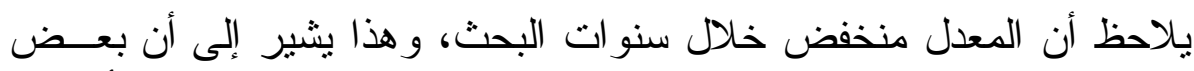

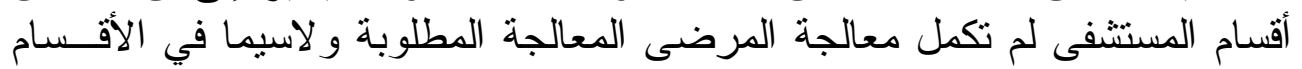

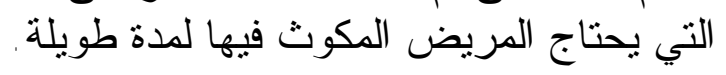

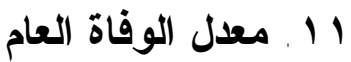

من خلال المعلومات المتوفرة تم إيجاد هذا المؤشر وكما في موضــح فـي

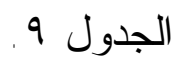

\begin{tabular}{|c|c|c|c|c|}
\hline \multicolumn{5}{|c|}{ معدل الجدواة العام 9} \\
\hline القياسيار & معدل الوفاة العام & عدد الر اقين & 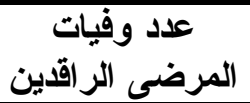 & السنة \\
\hline$\% \varepsilon-r$ & $\cdot, \wedge \varepsilon$ & IVAVO & $1 \leqslant \wedge$ & $r \ldots \varepsilon$ \\
\hline$=$ & $\cdot, V Y$ & 10707 & $11 \mathrm{~V}$ & $r \ldots o$ \\
\hline$=$ & $\cdot, 10$ & IVVIT & $10 Y$ & $r \ldots T$ \\
\hline
\end{tabular}

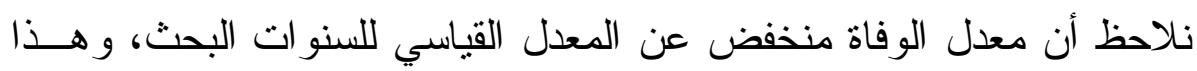
مؤشر جيد على الكفاءة في تقديم الخدمات إلى المرضى الرئ القدين فيها. 


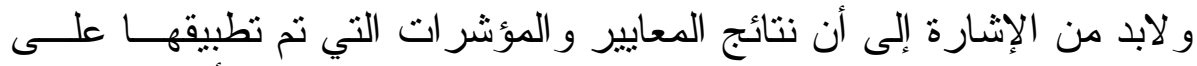

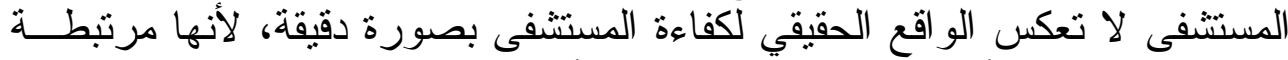

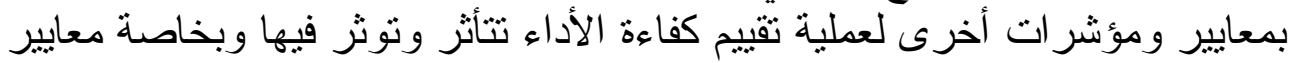

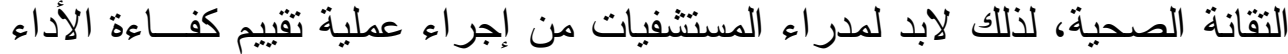
بمعظم المعايير و المؤشر ات لكي تكون النتائج أكثر دقة وأقرب ألقرب للو اقع.

الاستنتاجات

فيما يأتي الاستتتاجات التي تم التوصل إليها:

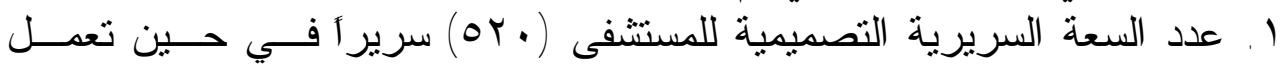

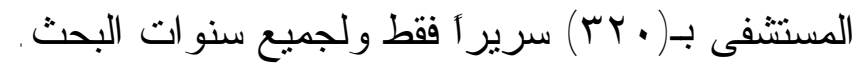

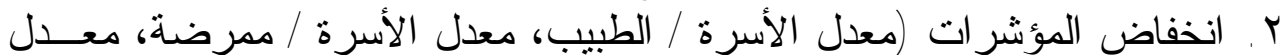

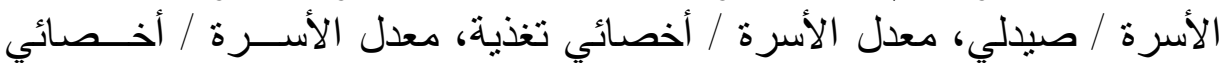

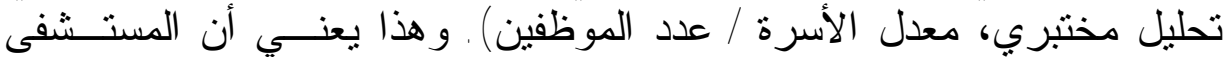

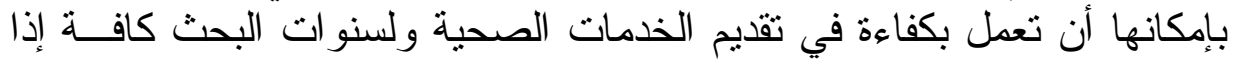

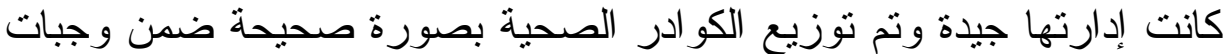

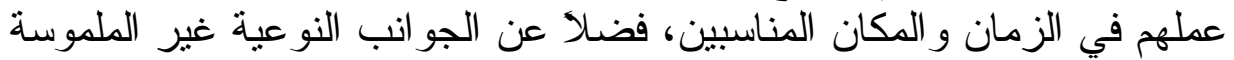

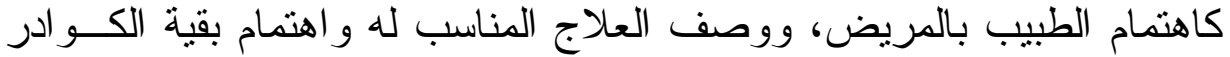

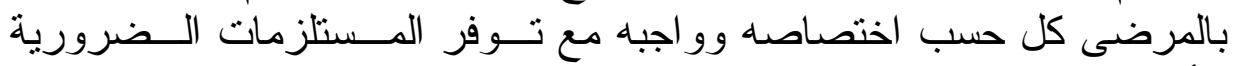

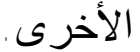

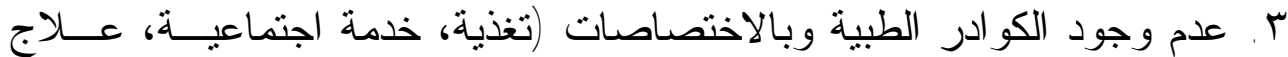

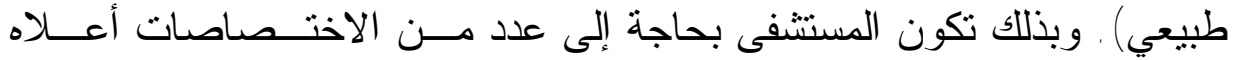
وحسب المعايير و المستوى المطلوب عالئي المياً وكما يأتي:

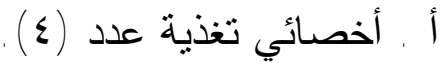

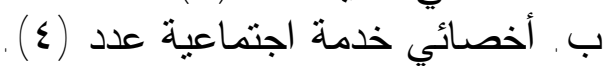

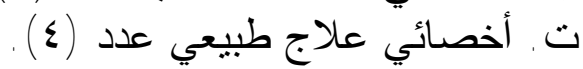

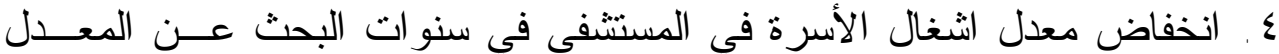
القياسي، و هو يعكس حالة من ضعف الستثمار المستثفى ككل أو لأحد أقسامها

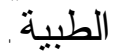

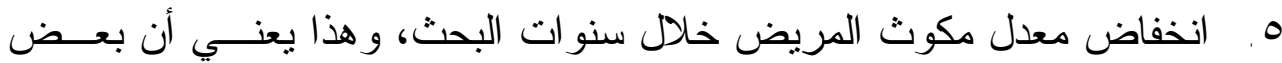

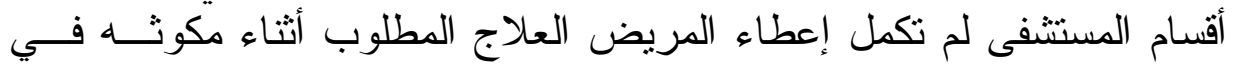

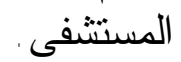
7 ا . انخفاض معدل الوفاة العام خلال سنوات البحث عن المعدل القياسي، وهذا يدل على أن المستثفى تعمل بكفاءة في مجال تقديم الخدمات الطبية للمو اطنين. 


\section{المقترحات}

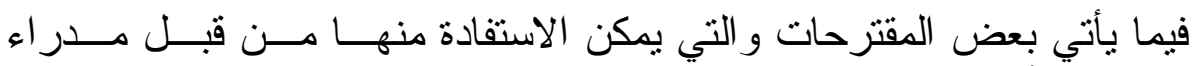

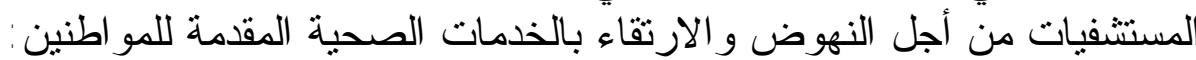

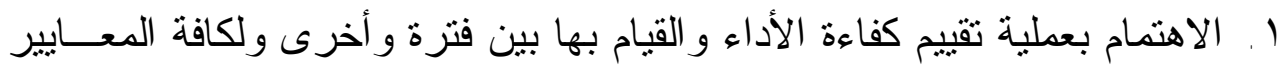

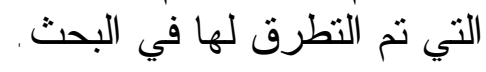

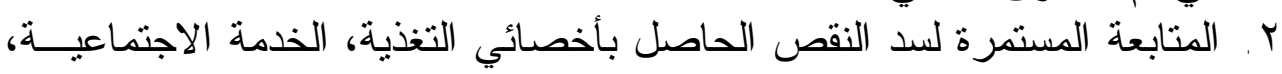
و العلاج طبيعي.

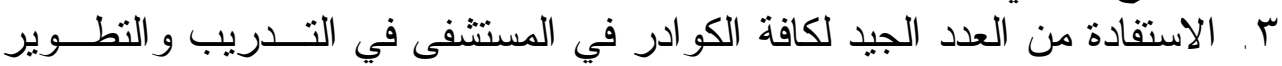

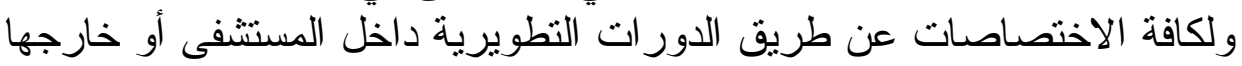
و بالتنسيق مع الجهات العلمية و الأكاديمية.

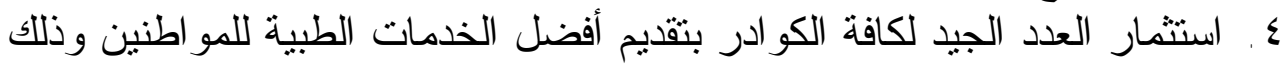

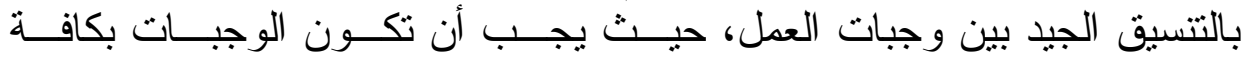

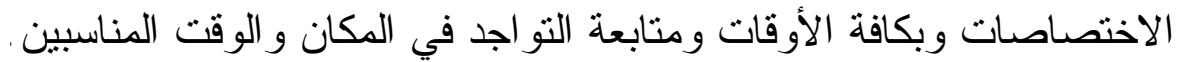

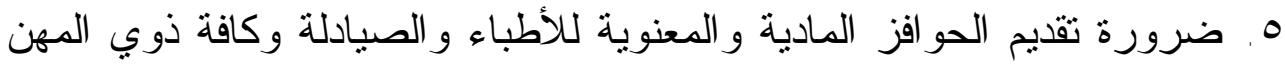

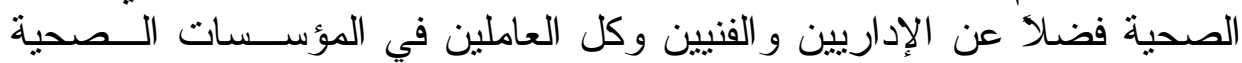

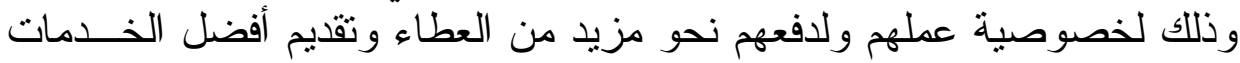

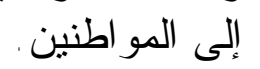

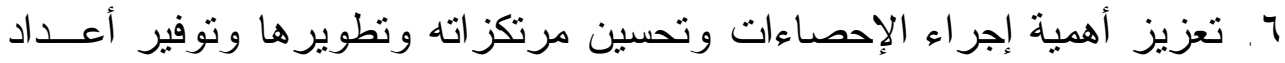

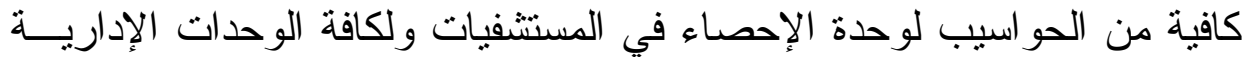

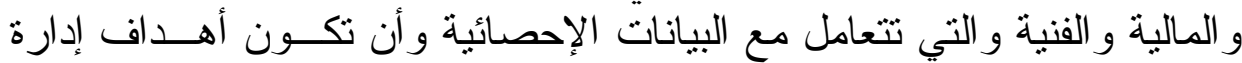

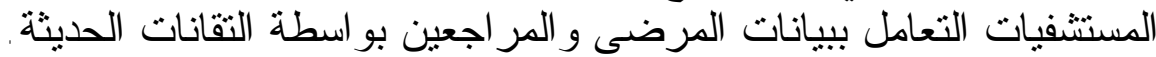
V. ل. دعم الملاكات الإحصائية ور عايتها مادياً ومعنوياً.

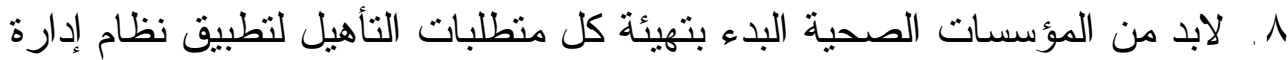

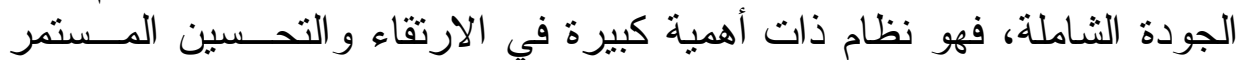
بمستوى جودة الخدمات الطبية المقدمة للمو اطنين.

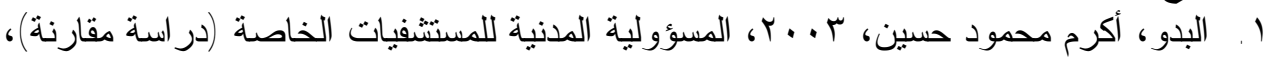

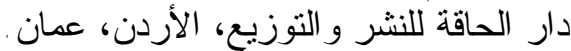

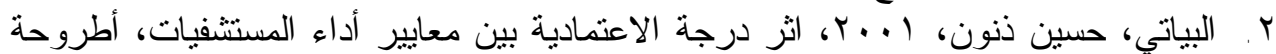

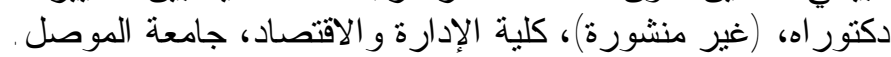

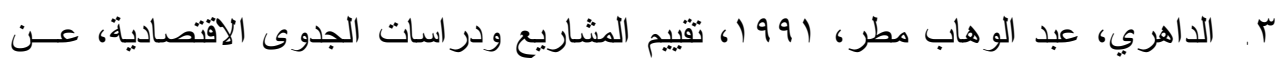

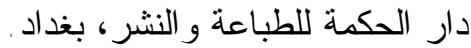

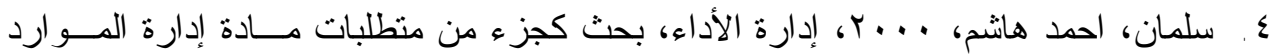

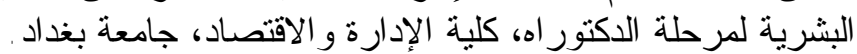


الصفار [010 [- [-

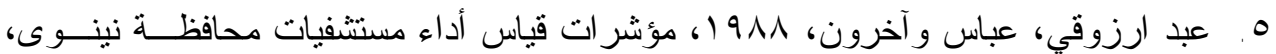

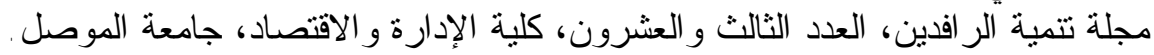

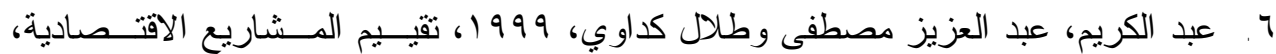
در اسة تحليل الجدوى الاقتصادية وكفاءة الأداء، دار الكتب للطباعة و النشر ، الطبعة الثانبة، التهاية

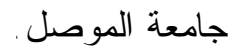

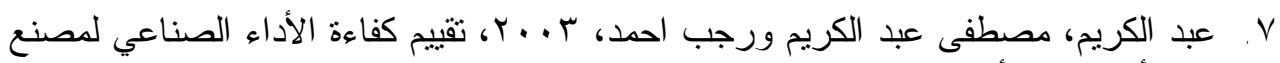

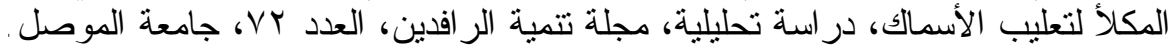

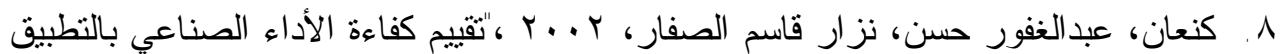

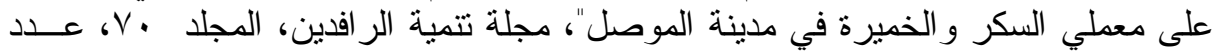

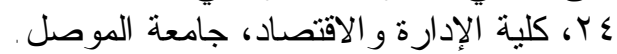

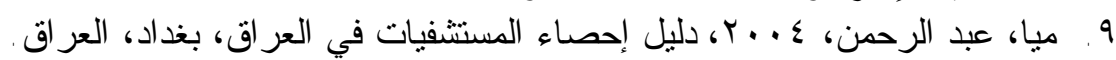

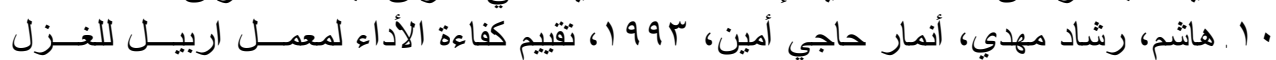

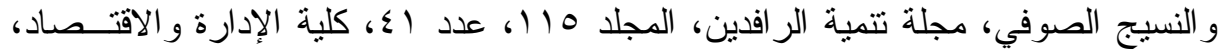

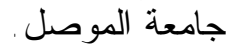

